\title{
Application of Vague Analytical Hierarchy Process to Prioritize the Challenges Facing Public Transportation in Dar Es Salaam City-Tanzania
}

\author{
Erick P. Massami \\ Unit for Applied Mathematics \\ Dar es Salaam Institute of Technology \\ Dar es Salaam, Tanzania
}

\author{
Benitha M. Myamba \\ Department of Logistics and Transport Studies \\ National Institute of Transport \\ Dar es Salaam, Tanzania
}

\begin{abstract}
Transportation is a key to the economy and social welfare; it makes mobility more accessible and enhances the social and economic interactions. On the other hand, the increase of urban population, pollution and other negative impacts has directly affected the existing transportation system in Dar es Salaam City - Tanzania. As the transportation challenges cannot be overcome simultaneously due to the scarcity of financial resources, a decision support tool is needed to prioritize these challenges. In this study, a composite model of Vague Set Theory (VST) and Analytical Hierarchy Process (AHP) is applied to appraise the challenges. The Vague Analytical Hierarchy Process (VAHP) uses opinions of experts collected from a survey questionnaire. The computational results reveal the ranking in descending order of the urban transportation challenges as poor traffic management, inadequacy of proper public transit service and inadequacy of road transport infrastructure. The results also depict that the VAHP model is a useful decision support tool for transport planners, transport policy makers and other industry stakeholders.
\end{abstract}

Keywords-Analytical Hierarchy Process; Vague Set; Urban Transportation; Transportation Challenge; Decision making

\section{INTRODUCTION}

The social-economic activities in any nation involve the movement of people and freight from one place to another. Transportation, as a major logistical element, plays a crucial role in this respect. For instance, the non-availability of products and/or services at the right time and right place can lead to negative consequences such as lost sales and customer dissatisfaction. Therefore efficient and effective transportation system is crucial for ensuring social-economic development [1].

Nonetheless, Dar es Salaam, the seaborne gateway in international trade for Tanzania and most of the East and Central African countries has been facing tremendous challenges in urban public transportation resulting from growth in travel demand and vehicular population. These challenges contribute to the malfunctioning of the city's public transport system. Due to resource constraints, it is impossible to tackle the causes of these challenges simultaneously. In addition, various actors may prioritize these challenges differently. Thus, it is essential to apply multi-criteria decision making technique i.e. Vague Analytic Hierarchy Process (VAHP) to optimally prioritize the transportation challenges in the city - Dar es Salaam. In particular, the Analytic Hierarchy Process (AHP) engineered by Saaty [2] is the most popular instrument in decision making for prioritizing alternatives. The AHP decision making approach combines deductive approach and systems approach of solving problems into one integrated logical framework and this makes it that much more effective in priority setting [3]. As it is hard for a decision maker to assess a factor/sub-factor based on a single number on a proposed scale of Judgement Number of Superiority, the application of the AHP alone could lead to a biased decision. Researchers and/or practitioners have suggested some approaches to overcome this challenge. In this study, we hybridize the AHP with Vague Soft Sets. The assessor's score on a particular factor/sub-factor based on the Vague Set Theory (VST) is given as an interval of crisp values matching with a particular linguistic term. Thus, the assessment of factors/sub-factors becomes much easier and unbiased.

This paper is structured as follows: Section II presents related studies; an overview of vague sets is presented in Section III; modeling procedure based on Vague Analytical Hierarchy Process is developed in Section IV; Section V gives application of the Vague Analytical Hierarchy Process to rank the challenges facing urban transportation in Dar es Salaam city - Tanzania. Lastly, conclusions are given in SectionVI.

\section{RELATED STUDIES}

The challenges facing public transportation in cities have been attributed by continuous growth in urban population, private vehicle ownership, ineffective and inefficient traffic management system and the ineffectiveness of public transport services which are the causes of traffic congestion with direct consequences on social and economic activities [4]. More specifically, the immediate effects of ineffective transportation systems are the rising cost of logistic activities and business services [4]. Arasan [5] describes effective urban transportation factors as adequate road networks, traffic management systems and reliable public transport services.

Harriet et al. [1] argue that the existing road transport infrastructure capacity in most cities in the developing economies has reached critical level and is unable to meet the huge demand from the increasing number of vehicles. Miller [6] stipulates that underinvestment in transport infrastructure 
has negative effects on logistic systems and the entire social and economic activities. Indeed, the rapid growth of China and other Asian countries is stimulated by more sophisticated infrastructure to support transportation and logistics [7].

Effective public transport service is essential for ensuring effective public transportation in urban areas. Xue et al. [8] present a study on urban road transportation strategy focusing on the mitigation of GHG emissions and public health damage, taking Xiamen city as a case study. Geng et al. [9] analyse the cost effectiveness and environmental benefits of various vehicles taking Shenyang - China as a case study. He et al. [10] estimate the energy consumption and $\mathrm{CO}_{2}$ emissions from China's urban passenger transportation sector up to year 2030. Fan et al. [11] formulates a model that minimizes hazmat risk and transportation cost subject to road closure constraints. Fatima and Kumar [12] examine the impact of a new public bus transit system in the city of Bardoli, Gujarat, India. Siedler [13] investigates under what conditions the Bus Rapid Transit (BRT) system can be regarded as the best solution to meet the challenges facing the Oslo metropolitan area.

Studies on effective traffic management are proposed by some researchers and practitioners. Malecki et al. [14] investigate the utilization of mobile devices to support traffic management system. Saleh et al. [15] propose a mechanism for vehicle routing based on the availability of updated traffic information. Schreffler et al. [16] suggest that effective traffic management can improve utilization of road networks at much lower cost than constructing new and expanding existing ones.

The challenges facing the road transportation sector are investigated by some researchers and practitioners. Msigwa [17] points out that the challenges of public transportation in fast-growing cities of Tanzania (e.g. Dar es Salaam) are vehicular growth, inadequacy of parking space, high frequency of accidents, transport infrastructure, and environmental and noise pollution.

The objective of this study is to prioritize the challenges confronting road based public transportation in the Dar es Salaam city-Tanzania. The proposed procedure is based on the hybrid model composed of the most popular decision making tool for ranking and/or selecting the alternatives (i.e. Analytical Hierarchy Process) and Soft Set Theory. We should note that the decision making based on the AHP alone can be biased due to the difficulty of assessing influential factors on the proposed scale of natural numbers. This biasness can be reduced or eliminated by the hybridization of the AHP with Vague Set Theory (VST). When using the VST, the assessor's score on a particular factor/sub-factor is given as an interval of values corresponding to a specific linguistic term.

\section{OVERVIEW OF VAGUE SETS}

Let $S=\left\{a_{1}, a_{2}, \ldots, a_{m}\right\}$ be the Universe. A vague set over $S$ is characterized by truth-membership function $t_{v}$ and a false membership function $f_{v}, t_{v}: S \rightarrow[0,1], f_{v}: S \rightarrow[0,1]$, where $t_{v}\left(a_{i}\right)$ is a lower bound (LB) for the membership degree of $a_{i}$ derived from the evidence in favour of $a_{i}$, $f_{v}\left(a_{i}\right)$ is a lower bound (LB) on the negation of $a_{i}$ derived from the evidence against $a_{i}$, and $t_{v}\left(a_{i}\right)+f_{v}\left(a_{i}\right) \leq$ 1.The membership degree of $a_{i}$ in the vague set belongs to the interval $\quad\left[t_{v}\left(a_{i}\right), 1-f_{v}\left(a_{i}\right)\right] \in[0,1]$. The vague value $\left[t_{v}\left(a_{i}\right), 1-f_{v}\left(a_{i}\right)\right]$ indicates that the exact membership degree $\mu_{v}\left(a_{i}\right) \in\left[t_{v}\left(a_{i}\right), 1-f_{v}\left(a_{i}\right)\right], t_{v}\left(a_{i}\right)+f_{v}\left(a_{i}\right) \leq 1$.

\section{Modelling Procedure Based on Vague ANALYTICAL HIERARCHY PROCESS}

We develop the Vague AHP model which consists of the following sequential steps:

Step 1: Establish Vague Judgement Number of Importance (i.e. Vague Assessment Scale). In this study, we adopt a scale suggested by Massami [18]. This scale has 0 as the lower bound and 1 as the upper bound. The scale has five (5) intervals each with the width of 0.2 units. The relation between linguistic operator of importance and Vague Judgement Number of Importance is listed in Table I.

Step 2: Establish Vague JudgementTable of Importance (VJTI) of the criteria/sub-criteria for an objective under consideration. This is as defined in Table II.

TABLE I. The RELATION BetWEEN Linguistic TERM AND VAguE JUDGEMENT NUMBER

\begin{tabular}{|l|l|l|l|l|l|}
\hline $\begin{array}{l}\text { Vague } \\
\text { Judgement } \\
\text { Number }\end{array}$ & {$[0.0,0.2]$} & {$[0.2,0.4]$} & {$[0.4,0.6]$} & {$[0.6,0.8]$} & {$[0.8,1.0]$} \\
\hline Importance & $\begin{array}{l}\text { Very } \\
\text { Low }\end{array}$ & Low & $\begin{array}{l}\text { Moderat } \\
\mathrm{e}\end{array}$ & High & $\begin{array}{l}\text { Very } \\
\text { High }\end{array}$ \\
\hline
\end{tabular}

TABLE II. VAGUE JUDGEMENT TABLE OF IMPORTANCE FOR THE CRITERIA OR SUB-CRITERIA

\begin{tabular}{|l|l|l|l|l|l|}
\hline $\begin{array}{l}\text { Factor } \\
\left(\mathbf{F}_{\mathbf{m}}\right)\end{array}$ & $\mathbf{P}_{1}$ & $\mathbf{P}_{2}$ & $\ldots$ & $\mathbf{P}_{\mathbf{N}}$ & $\frac{\mathbf{1}}{\mathbf{3 2}} \sum_{n=1}^{N}\left(\boldsymbol{a}_{\boldsymbol{m n}}+\boldsymbol{a}_{\boldsymbol{m} \boldsymbol{n}^{\prime}}\right)$ \\
\hline $\mathbf{F}_{\mathbf{1}}$ & {$\left[a_{11^{\prime}}, a_{\left.11^{\prime}\right]}\right.$} & {$\left[a_{12}, a_{\left.12^{\prime}\right]}\right.$} & $\ldots$ & {$\left[a_{1 N}, a_{\left.1 N^{\prime}\right]}\right.$} & $\frac{1}{32} \sum_{n=1}^{N}\left(a_{1 n}+a_{1 n^{\prime}}\right)$ \\
\hline $\mathbf{F}_{\mathbf{2}}$ & {$\left[a_{21}, a_{\left.21^{\prime}\right]}\right.$} & {$\left[a_{22}, a_{\left.22^{\prime}\right]}\right.$} & $\ldots$ & {$\left[a_{2 N}, a_{\left.2 N^{\prime}\right]}\right.$} & $\frac{1}{32} \sum_{n=1}^{N}\left(a_{2 n}+a_{2 n}\right)$ \\
\hline$\vdots$ & $\vdots$ & $\vdots$ & $\ldots$ & $\vdots$ & $\vdots$ \\
\hline $\mathbf{F}_{\mathbf{M}}$ & {$\left[a_{M 1}, a_{M 1^{\prime}}\right]$} & {$\left[a_{M 2}, a_{M 2^{\prime}}\right]$} & $\ldots$ & {$\left[a_{M N}, a_{M N}\right]$} & $\frac{1}{32} \sum_{n=1}^{N}\left(a_{M n}+a_{M n}\right)$ \\
\hline
\end{tabular}

Note: $\mathrm{P}_{\mathrm{n}}$ : Assessor $\mathrm{n} ; \frac{1}{32} \sum_{n=1}^{N}\left(a_{m n}+a_{m n}{ }^{\prime}\right)$ : Arithmetic mean of crisp assessment values for factor $F_{m}, m \in$ $\{1,2, \ldots M\}$

Step 3: Construct a Crisp Judgment Matrix of Importance (CJMI), C, whose elements are found by using the following mathematical relation.

$$
c_{m n}=\frac{\frac{1}{32} \sum_{n=1}^{N}\left(a_{m n}+a_{m n}{ }^{\prime}\right)}{\frac{1}{32} \sum_{n=1}^{N}\left(a_{k n}+a_{k n}{ }^{\prime}\right)}, \quad \forall m, k \in\{1,2, \ldots M\}
$$

Where $\left[a_{m n}, a_{m n}{ }^{\prime}\right]$ is a soft assessment value of factor $F_{m}$ by assessor $n$. 
Thus, matrix $\mathrm{C}$ is given by

$$
C=\left[\begin{array}{cccc}
c_{11} & c_{12} & \ldots & c_{1 N} \\
c_{21} & c_{22} & \ldots & c_{2 N} \\
\vdots & \vdots & \vdots & \vdots \\
c_{M 1} & c_{M 2} & \ldots & c_{M N}
\end{array}\right]_{M \times N}
$$

The entry $c_{m n}$ denotes the number that estimates the relative importance of factor $F_{m}$ when it is compared with factor $F_{n}$ for an objective under consideration (i.e. a level with respect to the upper level). The entry $c_{m n}$ must satisfy the following:

a) $c_{m n}>0$

b) $c_{m n}=\frac{1}{c_{n m}}$ (i.e. the matrix is a reciprocal one).

$c$ ) If $c_{m n}=c_{m k} . c_{k n}, \forall m, n, k$ then the weights are consistent (i.e. transitive).

d) If $m=n, \quad c_{m m}=c_{n n}=1$. Thus, $c_{m}$ and $c_{n}$ are of equal importance with respect to the objective in question.

Step 4: Find a weight vector i.e. priority vector $W$ of order $P$ (i.e. matrix size) satisfying the condition $A W=\lambda W$, the matrix $\mathrm{W}$ is called an eigenvector and $\lambda$ is an eigenvalue. If the Judgement Matrix is completely consistent, its maximum eigenvalue is equal to the dimension of the matrix i.e. $\lambda_{\max }=$ $P$. For matrices composed of elements made of human judgements, the condition $\quad c_{m n}=c_{m k} \cdot c_{k n}$ hardly hold as human judgments are inconsistent to a greater or lesser degree. Consequently, $A W=\lambda_{\max } W$ and $\lambda_{\max } \geq P$. $\left(\lambda_{\max }-P\right)$ indicates the inconsistency of the judgements. If $\lambda_{\text {max }}-$ $P=0$ then the judgments are completely consistent.

We define the priority vector $\mathrm{W}$ as

Where,

$$
W=\left[W_{F_{m}}\right], \quad m \in\{1,2, \ldots M\}
$$

$$
W_{F_{m}}=\frac{\frac{\sqrt[P]{\left(\prod_{n=1}^{N} c_{m n}\right)}}{\sum_{m=1}^{M} \sqrt[P]{\left(\prod_{n=1}^{N} c_{m n}\right)}}}{\sum_{\forall m}\left(\frac{\sqrt[P]{\left(\prod_{n=1}^{N} c_{m n}\right)}}{\sum_{m=1}^{M} \sqrt[P]{\left(\prod_{n=1}^{N} c_{m n}\right)}}\right)}, m \in\{1,2, \ldots M\}
$$

and $\quad \sum_{m=1}^{M} W_{F_{m}}=1$

Step 5: Find the weighted sum matrix $\left(C_{W}\right)$

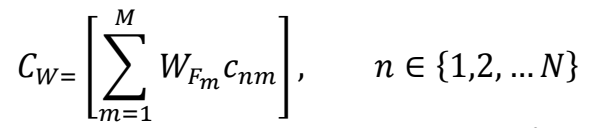

Step 6: Find the maximum eigenvalue $\left(\lambda_{\max }\right)$

The maximum characteristic root of the equation $A W=$ $\lambda W$ is given by

$$
\lambda_{\text {max }}=\frac{1}{P} \sum_{n=1}^{N}\left(\frac{\sum_{m=1}^{M} W_{F_{m}} c_{n m}}{W_{F_{n}}}\right), n \in\{1,2, \ldots N=M\}
$$

Step 7: Calculate a Consistency Index (CI)
The Consistency Index (CI) is given by

$$
C I=\frac{\lambda_{\max }-P}{P-1}
$$

Step 8: Compute a Consistency Ratio (CR)

A consistency ratio (CR) helps to check the consistency of the judgements and is calculated by dividing the Consistency Index (CI) by the Mean Random Consistency Index $\left(\mathrm{R}_{\mathrm{P}}\right)$. We use Table III for the mean random consistency index [19].

Thus,

$$
C R=\frac{C I}{R_{P}}
$$

If $\mathrm{CR}=0$ then we have a completely consistency case.

If $C R<0.1$ then we have a satisfying consistency case (i.e. the judgement matrix is considered to satisfy the unanimity).

If $C R>0.1$ then we have a non-satisfying consistency case (i.e. the judgements are too inconsistent to be reliable). Thus, a re-examination of the pairwise judgements is recommended until a CR less than or equal to 0.1 is achieved.

TABLE III. MEAN RANDOM CONSISTENCY INDEX FOR MATRIX DIMENSION $P$

\begin{tabular}{|l|l|l|l|l|l|l|l|}
\hline $\mathbf{P}$ & $\mathbf{1}$ & $\mathbf{2}$ & $\mathbf{3}$ & $\mathbf{4}$ & $\mathbf{5}$ & $\mathbf{6}$ & $\mathbf{7}$ \\
\hline $\mathbf{R}_{\mathbf{P}}$ & 0.00 & 0.00 & 0.52 & 0.89 & 1.12 & 1.26 & 1.36 \\
\hline $\mathbf{P}$ & 8 & 9 & 10 & 11 & 12 & 13 & 14 \\
\hline $\mathbf{R}_{\mathbf{P}}$ & 1.41 & 1.46 & 1.49 & 1.52 & 1.54 & 1.56 & 1.58 \\
\hline
\end{tabular}

Step 9: Compute Overall Priority of the 2nd Level Factor (e.g. sub- transportation challenge)

The local priorities of elements of different levels are aggregated to obtain final priorities of the sub-factors as follows:

$$
F P_{F_{m n}}=W_{F_{m}} \cdot W_{F_{m n}}
$$

$F P_{F_{m n}}$ : The Final Priority of the 2nd Level Factor $\left(\mathrm{F}_{\mathrm{mn}}\right)$;

$W_{F_{m n}}$ : Local Priority of $\mathrm{F}_{\mathrm{mn}}$ with respect to $\mathrm{F}_{\mathrm{m}}$;

$W_{F_{m}}$ : Local Priority of $\mathrm{F}_{\mathrm{m}}$ with respect to the goal.

\section{RANKING OF CHALLENGES FORURBAN TRANSPORTATION IN DAR ES SALAAM}

Through reviewing the literature and consulting local experts in the transport industry we identify three main challenges and sub-challenges that have a direct bearing impact on urban transportation in Dar es Salaam City. These prime challenges and sub-challenges are shown in Table IV. The selection of the challenges is also supported by Anin et al [20] who argue that an effective transportation system needs to consist of the following optimally combined elements: 
transport infrastructure, public transit system and traffic management system.

TABLE IV. TRANSPORTATION CHALLENGES IN DAR Es SALAAM City

\begin{tabular}{|c|c|}
\hline $\begin{array}{l}\text { Public Transportation } \\
\text { Challenge }\left(\mathbf{F}_{\mathbf{m}}\right)\end{array}$ & $\begin{array}{l}\text { Sub-Public Transportation Challenge } \\
\left(\mathbf{F}_{\mathrm{mn}}\right)\end{array}$ \\
\hline \multirow{3}{*}{$\begin{array}{l}\text { Inadequacy of road transport } \\
\text { infrastructure }\left(\mathrm{F}_{1}\right)\end{array}$} & $\begin{array}{l}\text { Inadequacy of road networks with lay-bys } \\
\left(\mathrm{F}_{11}\right)\end{array}$ \\
\hline & $\begin{array}{l}\text { Inadequacy of parking lot and terminals } \\
\left(\mathrm{F}_{12}\right)\end{array}$ \\
\hline & $\begin{array}{l}\text { Inadequacy of traffic lights and road sign } \\
\text { equipment }\left(\mathrm{F}_{13}\right)\end{array}$ \\
\hline \multirow{4}{*}{$\begin{array}{l}\text { Inadequacy of proper public } \\
\text { transit service }\left(\mathrm{F}_{2}\right)\end{array}$} & $\begin{array}{l}\text { Prevalence of vehicle emissions and noise } \\
\text { pollution }\left(\mathrm{F}_{21}\right)\end{array}$ \\
\hline & $\begin{array}{l}\text { Poor ethical status of drivers and } \\
\text { conductors }\left(\mathrm{F}_{22}\right)\end{array}$ \\
\hline & Occurrence of traffic accidents $\left(\mathrm{F}_{23}\right)$ \\
\hline & Inadequacy of road transport service $\left(\mathrm{F}_{24}\right)$ \\
\hline \multirow{3}{*}{$\begin{array}{l}\text { Inefficient traffic management } \\
\text { system }\left(\mathrm{F}_{3}\right)\end{array}$} & $\begin{array}{l}\text { Poor management of traffic lights and } \\
\text { other signals }\left(\mathrm{F}_{31}\right)\end{array}$ \\
\hline & $\begin{array}{l}\text { Poor management of drivers and } \\
\text { pedestrians' indiscipline on roads }\left(\mathrm{F}_{32}\right)\end{array}$ \\
\hline & $\begin{array}{l}\text { Poor management of vehicle breakdowns } \\
\text { and road accidents }\left(F_{33}\right)\end{array}$ \\
\hline
\end{tabular}

\section{A. Priority Vector Determination}

The study uses data from sixteen (16) experts who were supplied with survey questionnaires. This team consists of traffic police officers, practitioners and academia in the road transport subsector. The experts' data is used to compose the Vague Judgement Table of Importance (VJTI) from which the Crisp Judgement Matrix (CJM) is deduced.

\section{1) Assessment of Dar es Salaam City Transportation} System

The interviewed experts assessed the transportation system i.e. first level transportation challenges to give the vague judgmentTable V.

We apply equation (1) to get the elements of the crisp judgement matrix obtained by pair-wise comparison of the transportation challenges leading to ineffective urban transportation system as represented in Table VI.

TABLE V. VAgue Judgement VAlues From the AsSESSMENT OF First LEVEL TRANSPORTATION CHALLENGES

\begin{tabular}{|l|l|l|l|}
\hline Assessor & $\mathbf{F}_{1}$ & $\mathbf{F}_{2}$ & $\mathbf{F}_{3}$ \\
\hline $\mathbf{P}_{\mathbf{1}}$ & {$[0.8,1.0]$} & {$[0.8,1.0]$} & {$[0.6,0.8]$} \\
\hline $\mathbf{P}_{2}$ & {$[0.8,1.0]$} & {$[0.6,0.8]$} & {$[0.6,0.8]$} \\
\hline $\mathbf{P}_{3}$ & {$[0.2,0.4]$} & {$[0.4,0.6]$} & {$[0.2,0.4]$} \\
\hline $\mathbf{P}_{4}$ & {$[0.4,0.6]$} & {$[0.2,0.4]$} & {$[0.2,0.4]$} \\
\hline $\mathbf{P}_{5}$ & {$[0.8,1.0]$} & {$[0.6,0.8]$} & {$[0.4,0.6]$} \\
\hline $\mathbf{P}_{6}$ & {$[0.0,0.2]$} & {$[0.2,0.4]$} & {$[0.0,0.2]$} \\
\hline $\mathbf{P}_{7}$ & {$[0.4,0.6]$} & {$[0.4,0.6]$} & {$[0.4,0.6]$} \\
\hline
\end{tabular}

\begin{tabular}{|c|c|c|c|}
\hline $\mathbf{P}_{8}$ & {$[0.4,0.6]$} & {$[0.6,0.8]$} & {$[0.6,0.8]$} \\
\hline$P_{9}$ & {$[0.4,0.6]$} & {$[0.4,0.6]$} & {$[0.4,0.6]$} \\
\hline$P_{10}$ & {$[0.4,0.6]$} & {$[0.2,0.4]$} & {$[0.6,0.8]$} \\
\hline$P_{11}$ & {$[0.4,0.6]$} & {$[0.4,0.6]$} & {$[0.4,0.6]$} \\
\hline$P_{12}$ & {$[0.4,0.6]$} & {$[0.2,0.4]$} & {$[0.4,0.6]$} \\
\hline$P_{13}$ & {$[0.4,0.6]$} & {$[0.4,0.6]$} & {$[0.4,0.6]$} \\
\hline$P_{14}$ & {$[0.2,0.4]$} & {$[0.4,0.6]$} & {$[0.6,0.8]$} \\
\hline $\mathbf{P}_{15}$ & {$[0.4,0.6]$} & {$[0.4,0.6]$} & {$[0.4,0.6]$} \\
\hline$P_{16}$ & {$[0.2,0.4]$} & {$[0.2,0.4]$} & {$[0.0,0.2]$} \\
\hline$\frac{1}{32} \sum_{m=1}^{16}\left(a_{m n}+a_{m n}{ }^{\prime}\right)$ & $\frac{41}{80}$ & $\frac{1}{2}$ & $\frac{39}{80}$ \\
\hline
\end{tabular}

TABLE VI. CRISP JUdGEMENT MATRIX OF IMPORTANCE DUE TO INEFFECTIVE URBAN TRANSPORTATION SYSTEM

\begin{tabular}{|c|c|c|c|c|c|}
\hline Factor $\left(\mathbf{F}_{\mathrm{m}}\right)$ & $F_{1}$ & $\mathbf{F}_{2}$ & $\mathbf{F}_{3}$ & $\begin{array}{l}\text { Priority } \\
\text { Vector }\left(\mathrm{W} \mathrm{F}_{\mathrm{m}}\right)\end{array}$ & Rank \\
\hline$F_{1}$ & 1 & $\frac{40}{41}$ & $\frac{39}{41}$ & 0.3251 & 3 \\
\hline$F_{2}$ & $\frac{41}{40}$ & 1 & $\frac{39}{40}$ & 0.3332 & 2 \\
\hline $\mathbf{F}_{3}$ & $\frac{41}{39}$ & $\frac{40}{39}$ & 1 & 0.3417 & 1 \\
\hline
\end{tabular}

$c_{11}=\frac{\frac{1}{32} \sum_{m=1}^{16}\left(a_{m 1}+a_{m 1^{\prime}}\right)}{\frac{1}{32} \sum_{m=1}^{16}\left(a_{m 1}+a_{m 1^{\prime}}\right)}=1 ; c_{12}=\frac{\frac{1}{32} \sum_{m=1}^{16}\left(a_{m 2}+a_{m 2^{\prime}}\right)}{\frac{1}{32} \sum_{m=1}^{16}\left(a_{m 1}+a_{m 1^{\prime}}\right)}=\frac{40}{41} ;$

$c_{13}=\frac{\frac{1}{32} \sum_{m=1}^{16}\left(a_{m 3}+a_{m 3^{\prime}}\right)}{\frac{1}{32} \sum_{m=1}^{16}\left(a_{m 1}+a_{m 1^{\prime}}\right)}=\frac{39}{41}$

$c_{21}=\frac{\frac{1}{32} \sum_{m=1}^{16}\left(a_{m 1}+a_{m 1^{\prime}}\right)}{\frac{1}{32} \sum_{m=1}^{16}\left(a_{m 2}+a_{m 2^{\prime}}\right)}=\frac{41}{40} ; c_{22}=\frac{\frac{1}{32} \sum_{m=1}^{16}\left(a_{m 2}+a_{m 2^{\prime}}\right)}{\frac{1}{32} \sum_{m=1}^{16}\left(a_{m 2}+a_{m 2^{\prime}}\right)}=1$;

$c_{23}=\frac{\frac{1}{32} \sum_{m=1}^{16}\left(a_{m 3}+a_{m 3^{\prime}}\right)}{\frac{1}{32} \sum_{m=1}^{16}\left(a_{m 2}+a_{m 2^{\prime}}\right)}=\frac{39}{40}$

$c_{31}=\frac{\frac{1}{32} \sum_{m=1}^{16}\left(a_{m 1}+a_{m 1^{\prime}}\right)}{\frac{1}{32} \sum_{m=1}^{16}\left(a_{m 3}+a_{m 3^{\prime}}\right)}=\frac{41}{39} ; c_{32}=\frac{\frac{1}{32} \sum_{m=1}^{16}\left(a_{m 2}+a_{m 2^{\prime}}\right)}{\frac{1}{32} \sum_{m=1}^{16}\left(a_{m 3}+a_{m 3^{\prime}}\right)}=\frac{40}{39} ;$

$c_{33}=\frac{\frac{1}{32} \sum_{m=1}^{16}\left(a_{m 3}+a_{m 3^{\prime}}\right)}{\frac{1}{32} \sum_{m=1}^{16}\left(a_{m 3}+a_{m 3^{\prime}}\right)}=1$

We apply equation (3) to get the following elements of the weight vector.

$W_{F_{1}}=0.3251, W_{F_{2}}=0.3332, W_{F_{3}}=0.3417$

Obviously, the matrix as represented in Table VII is completely consistent i.e.

$$
\begin{gathered}
c_{m n}=c_{m k} \cdot c_{k n}, \quad \forall m, n, k \in\{1,2,3\} . \lambda_{\text {max }} \\
=\frac{1}{3} \sum_{n=1}^{3}\left(\frac{\sum_{m=1}^{3} W_{F_{m}} c_{n m}}{W_{F_{n}}}\right) \\
\lambda_{\text {max }}=\frac{1}{3}\left[\frac{\sum_{m=1}^{3}\left(W_{F_{m}} c_{1 m}\right)}{W_{F_{1}}}+\frac{\sum_{m=1}^{3}\left(W_{F_{m}} c_{2 m}\right)}{W_{F_{2}}}+\frac{\sum_{m=1}^{3}\left(W_{F_{m}} c_{3 m}\right)}{W_{F_{3}}}\right]=3.0000 \\
\mathrm{P}=3 \text { i.e. the matrix dimension }
\end{gathered}
$$




$$
\begin{gathered}
C I=\frac{\lambda_{\max }-P}{P-1}=\frac{3.0000-3}{3-1}=0 \\
P=3, R_{P}=0.52
\end{gathered}
$$

$C R=\frac{C I}{R_{3}}=\frac{0}{0.52}=0$ which means the crisp judgement matrix of importance is completely consistent.

The priority vector in Table VI reveals that poor traffic management is ranked the first urban transportation challenge of the three first level challenges. This result is largely contributed by poor management of drivers and pedestrians' indiscipline on roads (see the weight vector in Table XII). The second urban transportation challenge at the first level is inadequacy of proper public transit service which is aggravated by poor ethical status of drivers and conductors and inadequacy of mass transit service during peak hours (see Table X). The last first level challenge is inadequacy of road transport infrastructure which is largely contributed by the inadequacy of parking lot and terminals (see Table VIII). Nonetheless, the three challenges are approximately of equal significance i.e. $34.17 \%, 33.32 \%$ and $32.51 \%$. Thus, the overcoming process of the three challenges should be carried simultaneously.

2) Assessment of Transportation Challenges Leading to Inadequacy of Road Transport Infrastructure

The experts assessed the factors contributing to inadequacy of road transport infrastructure to give the soft judgement Table VII.

TABLE VII. VAGUE JUdGEMENT TABLE MADE FROM THE ASSESSMENT OF

\begin{tabular}{|c|c|c|c|}
\hline Assessor & $F_{11}$ & $F_{12}$ & $\mathbf{F}_{13}$ \\
\hline $\mathbf{P}_{1}$ & {$[0.8,1.0]$} & {$[0.8,1.0]$} & {$[0.6,0.8]$} \\
\hline $\mathbf{P}_{2}$ & {$[0.8,1.0]$} & {$[0.8,1.0]$} & {$[0.6,0.8]$} \\
\hline $\mathbf{P}_{3}$ & {$[0.0,0.2]$} & {$[0.0,0.2]$} & {$[0.2,0.4]$} \\
\hline $\mathbf{P}_{4}$ & {$[0.2,0.4]$} & {$[0.2,0.4]$} & {$[0.4,0.6]$} \\
\hline $\mathbf{P}_{5}$ & {$[0.8,1.0]$} & {$[0.4,0.6]$} & {$[0.2,0.4]$} \\
\hline $\mathbf{P}_{6}$ & {$[0.2,0.4]$} & {$[0.0,0.2]$} & {$[0.2,0.4]$} \\
\hline $\mathbf{P}_{7}$ & {$[0.2,0.4]$} & {$[0.0,0.2]$} & {$[0.4,0.6]$} \\
\hline $\mathbf{P}_{8}$ & {$[0.4,0.6]$} & {$[0.2,0.4]$} & {$[0.2,0.4]$} \\
\hline $\mathbf{P}_{9}$ & {$[0.4,0.6]$} & {$[0.0,0.2]$} & {$[0.8,1.0]$} \\
\hline$P_{10}$ & {$[0.4,0.6]$} & {$[0.0,0.2]$} & {$[0.4,0.6]$} \\
\hline $\mathbf{P}_{11}$ & {$[0.4,0.6]$} & {$[0.0,0.2]$} & {$[0.4,0.6]$} \\
\hline $\mathbf{P}_{12}$ & {$[0.4,0.6]$} & {$[0.4,0.6]$} & {$[0.2,0.4]$} \\
\hline $\mathbf{P}_{13}$ & {$[0.4,0.6]$} & {$[0.6,0.8]$} & {$[0.6,0.8]$} \\
\hline $\mathbf{P}_{14}$ & {$[0.2,0.4]$} & {$[0.2,0.4]$} & {$[0.2,0.4]$} \\
\hline $\mathbf{P}_{15}$ & {$[0.4,0.6]$} & {$[0.6,0.8]$} & {$[0.6,0.8]$} \\
\hline $\mathbf{P}_{16}$ & {$[0.2,0.4]$} & {$[0.2,0.4]$} & {$[0.2,0.4]$} \\
\hline$\frac{1}{32} \sum_{m=1}^{16}\left(a_{m n}+a_{m n}{ }^{\prime}\right)$ & $\frac{39}{80}$ & $\frac{3}{8}$ & $\frac{73}{160}$ \\
\hline
\end{tabular}
INADEQUACY OF ROAD TRANSPORT INFRASTRUCTURE

www.ijarai.thesai.org
We use equation (1) to get the elements of the crisp judgement matrix represented in Table VIII.

$c_{11}=\frac{\frac{1}{32} \sum_{m=1}^{16}\left(a_{m 1}+a_{m 1^{\prime}}\right)}{\frac{1}{32} \sum_{m=1}^{16}\left(a_{m 1}+a_{m 1^{\prime}}\right)}=1 ; c_{12}=\frac{\frac{1}{32} \sum_{m=1}^{16}\left(a_{m 2}+a_{m 2^{\prime}}\right)}{\frac{1}{32} \sum_{m=1}^{16}\left(a_{m 1}+a_{m 1^{\prime}}\right)}=\frac{10}{13}$;

$c_{13}=\frac{\frac{1}{32} \sum_{m=1}^{16}\left(a_{m 3}+a_{m 3^{\prime}}\right)}{\frac{1}{32} \sum_{m=1}^{16}\left(a_{m 1}+a_{m 1^{\prime}}\right)}=\frac{73}{78}$

$c_{21}=\frac{\frac{1}{32} \sum_{m=1}^{16}\left(a_{m 1}+a_{m 1^{\prime}}\right)}{\frac{1}{32} \sum_{m=1}^{16}\left(a_{m 2}+a_{m 2^{\prime}}\right)}=\frac{13}{10} ; c_{22}=\frac{\frac{1}{32} \sum_{m=1}^{16}\left(a_{m 2}+a_{m 2^{\prime}}\right)}{\frac{1}{32} \sum_{m=1}^{16}\left(a_{m 2}+a_{m 2^{\prime}}\right)}=1$;

$c_{23}=\frac{\frac{1}{32} \sum_{m=1}^{16}\left(a_{m 3}+a_{m 3^{\prime}}\right)}{\frac{1}{32} \sum_{m=1}^{16}\left(a_{m 2}+a_{m 2^{\prime}}\right)}=\frac{73}{60}$

$c_{31}=\frac{\frac{1}{32} \sum_{m=1}^{16}\left(a_{m 1}+a_{m 1^{\prime}}\right)}{\frac{1}{32} \sum_{m=1}^{16}\left(a_{m 3}+a_{m 3^{\prime}}\right)}=\frac{78}{73} ; c_{32}=\frac{\frac{1}{32} \sum_{m=1}^{16}\left(a_{m 2}+a_{m 2^{\prime}}\right)}{\frac{1}{32} \sum_{m=1}^{16}\left(a_{m 3}+a_{m 3^{\prime}}\right)}=\frac{60}{73}$;

$c_{33}=\frac{\frac{1}{32} \sum_{m=1}^{16}\left(a_{m 3}+a_{m 3^{\prime}}\right)}{\frac{1}{32} \sum_{m=1}^{16}\left(a_{m 3}+a_{m 3^{\prime}}\right)}=1$

We apply equation (3) to get the following elements of the weight vector whose set is

$\left\{W_{F_{11}}=0.2969, \quad W_{F_{12}}=0.3859, W_{F_{13}}=0.3172\right\}$

Since $c_{m n}=c_{m k} \cdot c_{k n}, \forall m, n, k \in\{1,2,3\}$, the matrix as represented in Table VIII is completely consistent. Thus, $\lambda_{\text {max }}=3, \mathrm{CI}=0, R_{3}=0.52, \mathrm{CR}=0$.

From Table VIII, the first challenge associated with inadequacy of road transport infrastructure is shortage of supply of parking lot and terminals to meet the current demand for the facilities (38.59\%). Both the Tanzania Roads Agency (TANROADS) and the Municipalities should increase their budget to finance these facilities. The second challenge is the shortage of traffic lights and road sign equipment $(31.72 \%)$. This calls for the TANROADS and Municipalities to invest more in traffic lights and road sign equipment to be placed at relevant locations. The last challenge is the shortage of road networks with lay-bys (29.69\%). Thus, the TANROADS and Municipalities should increase the supply of road networks to meet the current and projected demand.

TABLE VIII. CRISP JUDGEMENT MATRIX DUE TO INADEQUACY OF ROAD TRANSPORT INFRASTRUCTURE

\begin{tabular}{|l|l|l|l|l|l|}
\hline Factor $\left(\mathbf{F}_{\mathbf{m n}}\right)$ & $\mathbf{F}_{\mathbf{1 1}}$ & $\mathbf{F}_{\mathbf{1 2}}$ & $\mathbf{F}_{\mathbf{1 3}}$ & $\begin{array}{l}\text { Priority } \\
\text { Vector }\end{array}$ & Rank \\
\hline $\mathbf{F}_{\mathbf{1 1}}$ & 1 & $\frac{10}{13}$ & $\frac{73}{78}$ & 0.2969 & 3 \\
\hline $\mathbf{F}_{\mathbf{1 2}}$ & $\frac{13}{10}$ & 1 & $\frac{73}{60}$ & 0.3859 & 1 \\
\hline $\mathbf{F}_{13}$ & $\frac{78}{73}$ & $\frac{60}{73}$ & 1 & 0.3172 & 2 \\
\hline
\end{tabular}

3) Assessment of Transportation Challenges Leading to Public Transit Service

We use the experts' assessments on the transportation challenges associated with the inadequacy of public transit service to give the soft judgement in Table IX.

We apply equation (1) to get the elements of the crisp judgement matrix represented in Table $\mathrm{X}$. 


$$
\begin{aligned}
& c_{11}=\frac{\frac{1}{32} \sum_{m=1}^{16}\left(a_{m 1}+a_{m 1^{\prime}}\right)}{\frac{1}{32} \sum_{m=1}^{16}\left(a_{m 1}+a_{m 1^{\prime}}\right)}=1 ; c_{12}=\frac{\frac{1}{32} \sum_{m=1}^{16}\left(a_{m 2}+a_{m 2^{\prime}}\right)}{\frac{1}{32} \sum_{m=1}^{16}\left(a_{m 1}+a_{m 1^{\prime}}\right)}=\frac{17}{23} ; \\
& c_{13}=\frac{\frac{1}{32} \sum_{m=1}^{16}\left(a_{m 3}+a_{m 3^{\prime}}\right)}{\frac{1}{32} \sum_{m=1}^{16}\left(a_{m 1}+a_{m 1^{\prime}}\right)}=\frac{41}{46} \\
& c_{21}=\frac{\frac{1}{32} \sum_{m=1}^{16}\left(a_{m 1}+a_{m 1^{\prime}}\right)}{\frac{1}{32} \sum_{m=1}^{16}\left(a_{m 2}+a_{m 2^{\prime}}\right)}=\frac{23}{17} ; c_{22}=\frac{\frac{1}{32} \sum_{m=1}^{16}\left(a_{m 2}+a_{m 2^{\prime}}\right)}{\frac{1}{32} \sum_{m=1}^{16}\left(a_{m 2}+a_{m 2^{\prime}}\right)}=1 ; \\
& c_{23}=\frac{\frac{1}{32} \sum_{m=1}^{16}\left(a_{m 3}+a_{m 3^{\prime}}\right)}{\frac{1}{32} \sum_{m=1}^{16}\left(a_{m 2}+a_{m 2^{\prime}}\right)}=\frac{41}{34} \\
& c_{31}=\frac{\frac{1}{32} \sum_{m=1}^{16}\left(a_{m 1}+a_{m 1^{\prime}}\right)}{\frac{1}{32} \sum_{m=1}^{16}\left(a_{m 3}+a_{m 3^{\prime}}\right)}=\frac{46}{41} ; c_{32}=\frac{\frac{1}{32} \sum_{m=1}^{16}\left(a_{m 2}+a_{m 2^{\prime}}\right)}{\frac{1}{32} \sum_{m=1}^{16}\left(a_{m 3}+a_{m 3^{\prime}}\right)}=\frac{34}{41} ; \\
& c_{33}=\frac{\frac{1}{32} \sum_{m=1}^{16}\left(a_{m 3}+a_{m 3^{\prime}}\right)}{\frac{1}{32} \sum_{m=1}^{16}\left(a_{m 3}+a_{m 3^{\prime}}\right)}=1
\end{aligned}
$$

\begin{tabular}{|c|c|c|c|c|}
\hline Assessor & $\mathbf{F}_{21}$ & $\mathbf{F}_{22}$ & $\mathbf{F}_{23}$ & $\mathbf{F}_{24}$ \\
\hline $\mathbf{P}_{1}$ & {$[0.6,0.8]$} & {$[0.8,1.0]$} & {$[0.6,0.8]$} & {$[0.8,1.0]$} \\
\hline $\mathbf{P}_{2}$ & {$[0.8,1.0]$} & {$[0.8,1.0]$} & {$[0.6,0.8]$} & {$[0.6,0.8]$} \\
\hline $\mathbf{P}_{3}$ & {$[0.6,0.8]$} & {$[0.2,0.4]$} & {$[0.4,0.6]$} & {$[0.4,0.6]$} \\
\hline $\mathbf{P}_{4}$ & {$[0.0,0.2]$} & {$[0.2,0.4]$} & {$[0.4,0.6]$} & {$[0.4,0.6]$} \\
\hline $\mathbf{P}_{5}$ & {$[0.6,0.8]$} & {$[0.4,0.6]$} & {$[0.2,0.4]$} & {$[0.4,0.6]$} \\
\hline$P_{6}$ & {$[0.4,0.6]$} & {$[0.0,0.2]$} & {$[0.6,0.8]$} & {$[0.0,0.2]$} \\
\hline $\mathbf{P}_{7}$ & {$[0.8,1.0]$} & {$[0.2,0.4]$} & {$[0.4,0.6]$} & {$[0.4,0.6]$} \\
\hline $\mathbf{P}_{8}$ & {$[0.4,0.6]$} & {$[0.6,0.8]$} & {$[0.4,0.6]$} & {$[0.6,0.8]$} \\
\hline $\mathbf{P}_{9}$ & {$[0.6,0.8]$} & {$[0.2,0.4]$} & {$[0.6,0.8]$} & {$[0.4,0.6]$} \\
\hline $\mathbf{P}_{10}$ & {$[0.0,0.2]$} & {$[0.2,0.4]$} & {$[0.2,0.4]$} & {$[0.2,0.4]$} \\
\hline$P_{11}$ & {$[0.4,0.6]$} & {$[0.4,0.6]$} & {$[0.2,0.4]$} & {$[0.2,0.4]$} \\
\hline $\mathbf{P}_{12}$ & {$[0.4,0.6]$} & {$[0.0,0.2]$} & {$[0.4,0.6]$} & {$[0.2,0.4]$} \\
\hline $\mathbf{P}_{13}$ & {$[0.4,0.6]$} & {$[0.4,0.6]$} & {$[0.4,0.6]$} & {$[0.2,0.4]$} \\
\hline $\mathbf{P}_{14}$ & {$[0.8,1.0]$} & {$[0.2,0.4]$} & {$[0.4,0.6]$} & {$[0.2,0.4]$} \\
\hline $\mathbf{P}_{15}$ & {$[0.4,0.6]$} & {$[0.4,0.6]$} & {$[0.4,0.6]$} & {$[0.2,0.4]$} \\
\hline$P_{16}$ & {$[0.4,0.6]$} & {$[0.2,0.4]$} & {$[0.4,0.6]$} & {$[0.2,0.4]$} \\
\hline$\frac{1}{32} \sum_{m=1}^{16}\left(a_{m n}+a_{m n}\right)$ & $\frac{23}{40}$ & $\frac{17}{40}$ & $\frac{41}{80}$ & $\frac{7}{16}$ \\
\hline
\end{tabular}

TABLE IX. VAGUE JUdGEMENT VALUES DUE TO THE INADEQUACY OF Public TRANSIT SERVICE

$$
\begin{gathered}
c_{41}=\frac{\frac{1}{32} \sum_{m=1}^{16}\left(a_{m 1}+a_{m 1^{\prime}}\right)}{\frac{1}{32} \sum_{m=1}^{16}\left(a_{m 4}+a_{m 4^{\prime}}\right)}=\frac{46}{35} ; c_{42}=\frac{\frac{1}{32} \sum_{m=1}^{16}\left(a_{m 2}+a_{m 2^{\prime}}\right)}{\frac{1}{32} \sum_{m=1}^{16}\left(a_{m 4}+a_{m 4^{\prime}}\right)}=\frac{34}{35} ; \\
c_{43}=\frac{\frac{1}{32} \sum_{m=1}^{16}\left(a_{m 3}+a_{m 3^{\prime}}\right)}{\frac{1}{32} \sum_{m=1}^{16}\left(a_{m 4}+a_{m 4^{\prime}}\right)}=\frac{41}{34} \\
c_{14}=\frac{\frac{1}{32} \sum_{m=1}^{16}\left(a_{m 4}+a_{m 4^{\prime}}\right)}{\frac{1}{32} \sum_{m=1}^{16}\left(a_{m 1}+a_{m 1^{\prime}}\right)}=\frac{35}{46} ; c_{24}=\frac{\frac{1}{32} \sum_{m=1}^{16}\left(a_{m 4}+a_{m 4^{\prime}}\right)}{\frac{1}{32} \sum_{m=1}^{16}\left(a_{m 2}+a_{m 2^{\prime}}\right)}=\frac{35}{34} ; \\
c_{34}=\frac{\frac{1}{32} \sum_{m=1}^{16}\left(a_{m 4}+a_{m 4^{\prime}}\right)}{\frac{1}{32} \sum_{m=1}^{16}\left(a_{m 3}+a_{m 3^{\prime}}\right)}=\frac{35}{41} \\
c_{44}=\frac{\frac{1}{32} \sum_{m=1}^{16}\left(a_{m 4}+a_{m 4}^{\prime}\right)}{\frac{1}{32} \sum_{m=1}^{16}\left(a_{m 4}+a_{m 4}^{\prime}\right)}=1
\end{gathered}
$$

We apply equation (3) to get the following elements of the weight vector whose set is

$$
\left\{W_{F_{21}}=0.2088, W_{F_{22}}=0.2825, W_{F_{23}}=0.2343, W_{F_{24}}=0.2744\right\}
$$

Table $\mathrm{X}$ reveals the following. The first influential factor is poor ethical status of drivers and conductors $(28.25 \%)$. This necessitates routine training in interpersonal skills and customer service to this group of stakeholders. The training could be offered by the Tanzania traffic policy department, the National Institute of Transport (NIT) or any training firm with expertise in the transport industry. The second factor is inadequacy of road transport service during peak hours $(27.44 \%)$. As there is no barrier for the new entrants in this particular market i.e. for most routes of the city, the door is open for potential investors i.e. transport operators to provide public transit services. The third factor is the occurrence of traffic accidents (23.43\%). As such, all three aspects contributing to road traffic accidents i.e. human element, vehicle element and road environment should be improved by the relevant parties. The last factor is the prevalence of vehicle emissions and noise pollution (20.88\%). Consequently, all stakeholders including the Surface and Marine Transport Regulatory Authority (SUMATRA - Tanzania), vehicle owners and operators should take deliberate efforts to overcome the challenge.

TABLE X. CRISP JUDGEMENT MATRIX DUE TO THE INADEQUACY OF Public TRANSIT SERVICE

\begin{tabular}{|l|l|l|l|l|l|l|}
\hline $\begin{array}{l}\text { Factor } \\
\left(\mathbf{F}_{\mathbf{m n}}\right)\end{array}$ & $\mathbf{F}_{21}$ & $\mathbf{F}_{22}$ & $\mathbf{F}_{23}$ & $\mathbf{F}_{24}$ & $\begin{array}{l}\text { Priority } \\
\text { Vector }\end{array}$ & Rank \\
\hline $\mathbf{F}_{21}$ & 1 & $\frac{17}{23}$ & $\frac{41}{46}$ & $\frac{35}{46}$ & 0.2088 & 4 \\
\hline $\mathbf{F}_{22}$ & $\frac{23}{17}$ & 1 & $\frac{41}{34}$ & $\frac{35}{34}$ & 0.2825 & 1 \\
\hline $\mathbf{F}_{23}$ & $\frac{46}{41}$ & $\frac{34}{41}$ & 1 & $\frac{35}{41}$ & 0.2343 & 3 \\
\hline$F_{24}$ & $\frac{46}{35}$ & $\frac{34}{35}$ & $\frac{41}{35}$ & 1 & 0.2744 & 2 \\
\hline
\end{tabular}

Since $c_{m n}=c_{m k} \cdot c_{k n}, \forall m, n, k \in\{1,2,3,4\}$, the matrix above is completely consistent. Thus, $\lambda_{\max }=4, \mathrm{CI}=0$, $R_{4}=0.89, \mathrm{CR}=0$.

4) Assessment of Transportation Challenges Related to InefficientTraffic Management System

The experts assessed the factors contributing to inefficient traffic management system to give the vague judgement as represented in Table XI.

We apply equation (1) to get the elements of the crisp judgement matrix represented in Table XII.

$$
\begin{aligned}
& c_{11}=\frac{\frac{1}{32} \sum_{m=1}^{16}\left(a_{m 1}+a_{m 1^{\prime}}\right)}{\frac{1}{32} \sum_{m=1}^{16}\left(a_{m 1}+a_{m 1^{\prime}}\right)}=1 ; c_{12}=\frac{\frac{1}{32} \sum_{m=1}^{16}\left(a_{m 2}+a_{m 2^{\prime}}\right)}{\frac{1}{32} \sum_{m=1}^{16}\left(a_{m 1}+a_{m 1^{\prime}}\right)}=\frac{31}{36} ; \\
& c_{13}=\frac{\frac{1}{32} \sum_{m=1}^{16}\left(a_{m 3}+a_{m 3^{\prime}}\right)}{\frac{1}{32} \sum_{m=1}^{16}\left(a_{m 1}+a_{m 1^{\prime}}\right)}=\frac{17}{18}
\end{aligned}
$$




$$
\begin{aligned}
& c_{21}=\frac{\frac{1}{32} \sum_{m=1}^{16}\left(a_{m 1}+a_{m 1^{\prime}}\right)}{\frac{1}{32} \sum_{m=1}^{16}\left(a_{m 2}+a_{m 2^{\prime}}\right)}=\frac{36}{31} ; c_{22}=\frac{\frac{1}{32} \sum_{m=1}^{16}\left(a_{m 2}+a_{m 2^{\prime}}\right)}{\frac{1}{32} \sum_{m=1}^{16}\left(a_{m 2}+a_{m 2^{\prime}}\right)}=1 ; \\
& c_{23}=\frac{\frac{1}{32} \sum_{m=1}^{16}\left(a_{m 3}+a_{m 3^{\prime}}\right)}{\frac{1}{32} \sum_{m=1}^{16}\left(a_{m 2}+a_{m 2^{\prime}}\right)}=\frac{34}{31}
\end{aligned}
$$

TABLE XI. VAGUE JUdGEMENT TABLE DUE To INEFFICIENT TRAFFIC

\begin{tabular}{|c|c|c|c|}
\hline Assessor & $\mathbf{F}_{31}$ & $\mathbf{F}_{32}$ & $\mathbf{F}_{33}$ \\
\hline $\mathbf{P}_{1}$ & {$[0.6,0.8]$} & {$[0.6,0.8]$} & {$[0.4,0.6]$} \\
\hline $\mathbf{P}_{2}$ & {$[0.6,0.8]$} & {$[0.8,1.0]$} & {$[0.6,0.8]$} \\
\hline $\mathbf{P}_{3}$ & {$[0.2,0.4]$} & {$[0.0,0.2]$} & {$[0.4,0.6]$} \\
\hline $\mathbf{P}_{4}$ & {$[0.2,0.4]$} & {$[0.2,0.4]$} & {$[0.2,0.4]$} \\
\hline $\mathbf{P}_{5}$ & {$[0.6,0.8]$} & {$[0.4,0.6]$} & {$[0.0,0.2]$} \\
\hline$P_{6}$ & {$[0.2,0.4]$} & {$[0.0,0.2]$} & {$[0.0,0.2]$} \\
\hline $\mathbf{P}_{7}$ & {$[0.0,0.2]$} & {$[0.2,0.4]$} & {$[0.2,0.4]$} \\
\hline $\mathbf{P}_{8}$ & {$[0.4,0.6]$} & {$[0.2,0.4]$} & {$[0.4,0.6]$} \\
\hline $\mathbf{P}_{9}$ & {$[0.4,0.6]$} & {$[0.0,0.2]$} & {$[0.4,0.6]$} \\
\hline $\mathbf{P}_{10}$ & {$[0.2,0.4]$} & {$[0.2,0.4]$} & {$[0.4,0.6]$} \\
\hline$P_{11}$ & {$[0.4,0.6]$} & {$[0.2,0.4]$} & {$[0.4,0.6]$} \\
\hline $\mathbf{P}_{12}$ & {$[0.2,0.4]$} & {$[0.4,0.6]$} & {$[0.6,0.8]$} \\
\hline $\mathbf{P}_{13}$ & {$[0.6,0.8]$} & {$[0.2,0.4]$} & {$[0.4,0.6]$} \\
\hline $\mathbf{P}_{14}$ & {$[0.2,0.4]$} & {$[0.8,1.0]$} & {$[0.2,0.4]$} \\
\hline $\mathbf{P}_{15}$ & {$[0.6,0.8]$} & {$[0.2,0.4]$} & {$[0.4,0.6]$} \\
\hline $\mathbf{P}_{16}$ & {$[0.2,0.4]$} & {$[0.2,0.4]$} & {$[0.2,0.4]$} \\
\hline$\frac{1}{32} \sum_{m=1}^{16}\left(a_{m n}+a_{m n}\right)$ & $\frac{9}{20}$ & $\frac{31}{80}$ & $\frac{17}{40}$ \\
\hline
\end{tabular}
MANAGEMENT SYSTEM

TABLE XII. CRISP JUdGEMENT MATRIX DUE TO THE INEFFICIENCY OF TRAFFIC MANAGEMENT SYSTEM

\begin{tabular}{|l|c|c|c|l|l|}
\hline Factor $\left(\mathbf{F}_{\mathbf{m n}}\right)$ & $\mathbf{F}_{\mathbf{3 1}}$ & $\mathbf{F}_{\mathbf{3 2}}$ & $\mathbf{F}_{\mathbf{3 3}}$ & $\begin{array}{l}\text { Priority } \\
\text { Vector }\end{array}$ & Rank \\
\hline $\mathbf{F}_{\mathbf{3 1}}$ & 1 & $\frac{31}{36}$ & $\frac{17}{18}$ & 0.3106 & 3 \\
\hline $\mathbf{F}_{\mathbf{3 2}}$ & $\frac{36}{31}$ & 1 & $\frac{34}{31}$ & 0.3606 & 1 \\
\hline $\mathbf{F}_{\mathbf{3 3}}$ & $\frac{18}{17}$ & $\frac{31}{34}$ & 1 & 0.3288 & 2 \\
\hline
\end{tabular}

Since $c_{m n}=c_{m k} \cdot c_{k n}, \forall m, n, k \in\{1,2,3\}$, the matrix above is completely consistent. Thus, $\lambda_{\max }=3, \mathrm{CI}=0$, $R_{3}=0.52, \mathrm{CR}=0$.

$c_{31}=\frac{\frac{1}{32} \sum_{m=1}^{16}\left(a_{m 1}+a_{m 1^{\prime}}\right)}{\frac{1}{32} \sum_{m=1}^{16}\left(a_{m 3}+a_{m 3^{\prime}}\right)}=\frac{18}{17} ; c_{32}=\frac{\frac{1}{32} \sum_{m=1}^{16}\left(a_{m 2}+a_{m 2^{\prime}}\right)}{\frac{1}{32} \sum_{m=1}^{16}\left(a_{m 3}+a_{m 3^{\prime}}\right)}=\frac{31}{34} ;$

$c_{33}=\frac{\frac{1}{32} \sum_{m=1}^{16}\left(a_{m 3}+a_{m 3^{\prime}}\right)}{\frac{1}{32} \sum_{m=1}^{16}\left(a_{m 3}+a_{m 3^{\prime}}\right)}=1$

We apply equation (3) to get the following elements of the weight vector whose set is

$$
\left\{W_{F_{31}}=0.3106, W_{F_{32}}=0.3606, W_{F_{33}}=0.3288\right\}
$$

According to experts' views, the first influential factor on inefficient traffic management system in Dar es Salaam city is poor management of drivers and pedestrians' indiscipline $(36.06 \%)$. This challenge reveals that the Tanzania traffic police department is alleged to provide training to the public on road signs and safety awareness and enforce properly road traffic regulations.

The second factor is poor management of vehicle breakdowns and road accidents (32.88\%). Thus, all human, vehicle and road environment aspects need to be improved to curb this problem. The last challenge is poor management of traffic lights and other signals (31.06\%). This challenge exists when traffic lights and road signs are not maintained properly. The Tanzania Roads Agency (TANROADS) should carry out routine check and keep abreast of technology (technologies) which can enhance the optimisation of traffic flows.

\section{B. Ranking of the Challenges for Urban Public \\ Transpotationt in Dar esSalaam City}

We apply equation (9) to determine the overall priority of the transportation challenges as represented in Table XIII.

\begin{tabular}{|c|c|c|c|c|c|}
\hline $\begin{array}{l}\text { Factor } \\
\left(\boldsymbol{F}_{\boldsymbol{m}}\right)\end{array}$ & $\begin{array}{l}\text { Local } \\
\text { weight } \\
\left(W_{F_{m}}\right)\end{array}$ & $\begin{array}{l}\begin{array}{l}\text { Sub- } \\
\text { factor }\end{array} \\
\left(F_{m n}\right)\end{array}$ & $\begin{array}{l}\text { Local } \\
\text { weight } \\
\left(W_{F_{m n}}\right)\end{array}$ & $\begin{array}{l}\text { Overall } \\
\text { Priority } \\
W_{F_{m}} \cdot W_{F_{m n}}\end{array}$ & Rank \\
\hline \multirow{3}{*}{$\mathbf{F}_{1}$} & \multirow{3}{*}{0.3251} & $F_{11}$ & 0.2969 & $\begin{array}{l}W_{F_{1}} \cdot W_{F_{11}} \\
=0.0965\end{array}$ & 6 \\
\hline & & $F_{12}$ & 0.3859 & $\begin{array}{l}W_{F_{1}} \cdot W_{F_{12}} \\
=0.1255\end{array}$ & 1 \\
\hline & & $F_{13}$ & 0.3172 & $\begin{array}{l}W_{F_{1}} \cdot W_{F_{13}} \\
=0.1031\end{array}$ & 5 \\
\hline \multirow{4}{*}{$\mathbf{F}_{2}$} & \multirow{4}{*}{0.3332} & $F_{21}$ & 0.2088 & $\begin{array}{l}W_{F_{2}} \cdot W_{F_{21}} \\
=0.0696\end{array}$ & 10 \\
\hline & & $F_{22}$ & 0.2825 & $\begin{array}{l}W_{F_{2}} \cdot W_{F_{22}} \\
=0.0941\end{array}$ & 7 \\
\hline & & $F_{23}$ & 0.2343 & $\begin{array}{l}W_{F_{2}} \cdot W_{F_{23}} \\
=0.0781\end{array}$ & 9 \\
\hline & & $F_{24}$ & 0.2744 & $\begin{array}{l}W_{F_{2}} \cdot W_{F_{24}} \\
=0.0914\end{array}$ & 8 \\
\hline \multirow{3}{*}{$\mathbf{F}_{3}$} & \multirow{3}{*}{0.3417} & $F_{31}$ & 0.3106 & $\begin{array}{l}W_{F_{3}} \cdot W_{F_{31}} \\
=0.1061\end{array}$ & 4 \\
\hline & & $F_{32}$ & 0.3606 & $\begin{array}{l}W_{F_{3}} \cdot W_{F_{32}} \\
=0.1232\end{array}$ & 2 \\
\hline & & $F_{33}$ & 0.3288 & $\begin{array}{l}W_{F_{3}} \cdot W_{F_{33}} \\
=0.1124\end{array}$ & 3 \\
\hline
\end{tabular}

TABLE XIII. MATRIX OF PRIORITIZATION OF TRANSPORTATION CHALLENGES IN DAR ES SALAAM CITY

Table XIII reveals the overall prioritization of the urban public transportation sub-challenges as follows: Inadequacy of 
parking lot and terminals; poor management of drivers and pedestrians' indiscipline; poor management of vehicle breakdowns and road accidents; poor management of traffic lights and signals; inadequacy of traffic lights and road sign equipment; inadequacy of road networks with lay-bys; poor ethical status of drivers and conductors; inadequacy of road transport service; occurrence of traffic accidents; and prevalence of vehicle emissions and noise pollution.

As there is limited financial resources attached to the management issues and investment of new facilities to overcome the proposed challenges, the government can use the ranking of the challenges for prioritization purposes. More specifically, the proposed VAHP model can be used as an investment appraisal tool for selecting the best alternative/project in other industries.

\section{CONCLUSIONS}

Rapid urbanization in Dar es Salaam city - Tanzania has led to the increased demand for public transport services which in turn necessitates improved transport infrastructure, traffic management and public transit services. Limited financial resources make these transportation challenges to be prioritized and allocate funds accordingly. In this paper, we formulate a multi-criteria decision making problem and appraise the transportation challenges using the Vague Analytical Hierarchy Process (VAHP) Model. The results of ranking of the challenges in descending order are poor traffic management, inadequacy of proper public transit service and inadequacy of road transport infrastructure. The findings also reveal that the hybridization of the AHP with the Vague Sets, improve the consistency of the Crisp Judgement Matrices (CJM). Moreover, the computational results validate the VAHP model which can be applied in other research fields as a decision support tool. Our future research direction is to model a hybrid decision support tool composed of Vague Sets, Soft Sets and Rough Sets to assess rural public transportation challenges in Tanzania.

\section{REFERENCES}

[1] T. Harriet, K. Poku, \& E.K. Anin, "Logistics Inefficiencies of Urban Transportation System in Ghana," .International Journal of Humanities and Social Science, 3(5): 308-314, 2003.

[2] T.L. Saaty, "The analytic hierarchy process: planning, priority setting and resource allocation," McGraw-Hill: New York, 1980

[3] S. Yedla, \& R.M. Shrestha, "Application of Analytic Hierarchy Process to Prioritize Urban Transport Options- Comparative Analysis of Group Aggregation Method, 'Indira Gandhi Institute of Development Research, Mumbai, 2007.
[4] World Bank, “Urban Transportation,"Online available at www.web.worldbank.org (Accessed August 09, 2015), 2011.

[5] T.V. Arasan, "Urban Transportation systems planning," Unpublished.

[6] S.Miller, "The challenges of logistics performance," Available at http://EzineArticles.com/?expert=sammiller (Accessed August, 2012), 2012.

[7] A.M. Rodrigues, D.J. Bowersox, \& R.J. Calantone, "Estimation of global and natural logistics expenditure: 2002 data update"Journal of Business Logistics, 26(2): 1 - 15, 2005.

[8] X. Xue, Y. Ren, S. Cui, J. Lin, W.Huang, \& J. Zhou, "Integrated analysis of GHGs and public health damage mitigation for developing urban road transportation strategies,"Transportation Research Part D: Transport and Environment, 35: 84-103, 2015.

[9] Y. Geng, Z. Ma, B. Xue, W. Ren, Z. Liu, \& T. Fujita, "Co-benefit evaluation for urban public transportation-sector-a case of Shenyang, China"Journal of Cleaner Production, 58: 82-91, 2013.

[10] D. He, H. Liu, K. He, F. Meng, Y. Jiang, M. Wang, J. Zhou, P. Calthorpe, J. Guo, Z. Yao, \& Q. Wang, "Energy use of, and $\mathrm{CO} 2$ emissions from China's urban passenger transportation sector-carbon mitigation scenarios upon the transportation mode choices," Transportation Research Part A: Policy and Practice, 53: 53-67, 2013.

[11] T. Fan, W. Chiang, \& R. Russel, "Modeling urban hazmat transportation with road closure consideration,"Transportation Research Part D: Transport and Environment, 35: 104-115, 2015.

[12] E. Fatima, \& R. Kumar, "Introduction of public bus transit in Indian cities,"International Journal of Sustainable Built Environment, 3(1): 2734,2014

[13] C.E. Siedler, "Can Bus Rapid Transit Be a Sustainable Means of Public Transport in Fast Growing Cities? Empirical Evidence in the case of Oslo," Transportation Research Procedia, 1(1): 109-120, 2014.

[14] K. Malecki, S. Iwan, \& K. Kijewska, "Influence of Intelligent Transportation Systems on Reduction of the Environmental Negative Impact of Urban Freight Transport Based on Szczecin Example,"Procedia-Social and Behavioral Sciences, 151: 215-229, 2014

[15] Y. Saleh, A. Tofigh, \& A. Zahra, "Transportation Routing in Urban Environments Using Updated Traffic Information Provided Through Vehicular Communications,"Journal of Transportation Systems Engineering and Information Technology, 14(5): 23-36, 2014.

[16] E. Schreffler, D. Gopalakrishna, D. Vary, D. Friedenfeld, B. Kuhn, C. Dusza, R. Klein \& A. Rosas, "Integrating demand management into the transportation planning process: A desk refere3nce,"Jounal of Institute of Transportation Engineers, 82(1): 38-41, 2012.

[17] R.E. Msigwa, "Challenges Facing Urban Transportation in Tanzania. Mathematical Theory and Modelling," 3(5): 18-26, 2013.

[18] E.P. Massami, "Risk Assessment of Port Competitiveness Based on Vague Soft Sets,"Transport Policy, In Press.

[19] H. Shang, (ed.), "Actuarial Science: Theory and Methodology,"Beijing: Higher Education Press, 2006.

[20] E.K. Anin, J. Annan, \& F.A. Otchere, "Evaluating the Role of Mass Transit and its Effect on Fuel Efficiency in the Kumasi Metropolis, Ghana,"International Journal of Business and Social Research, 3(3): 107-116, 2013. 